\title{
H3K36 dimethylation by MMSET promotes classical non-homologous end-joining at unprotected telomeres
}

\author{
Inge de Krijger ${ }^{1} \cdot$ Jaco van der Torre ${ }^{1} \cdot$ Marieke H. Peuscher $^{1} \cdot$ Mathias Eder $^{1}$ - Jacqueline J. L. Jacobs $\mathbb{D}^{1}$
}

Received: 10 January 2020 / Revised: 12 May 2020 / Accepted: 15 May 2020 / Published online: 29 May 2020

(c) The Author(s) 2020. This article is published with open access

\begin{abstract}
The epigenetic environment plays an important role in DNA damage recognition and repair, both at DNA double-strand breaks and at deprotected telomeres. To increase understanding on how DNA damage responses (DDR) at deprotected telomeres are regulated by modification and remodeling of telomeric chromatin we screened 38 methyltransferases for their ability to promote telomere dysfunction-induced genomic instability. As top hit we identified MMSET, a histone methyltransferase (HMT) causally linked to multiple myeloma and Wolf-Hirschhorn syndrome. We show that MMSET promotes non-homologous end-joining (NHEJ) at deprotected telomeres through Ligase4-dependent classical NHEJ, and does not contribute to Ligase3-dependent alternative NHEJ. Moreover, we show that this is dependent on the catalytic activity of MMSET, enabled by its SET-domain. Indeed, in absence of MMSET H3K36-dimethylation (H3K36me2) decreases, both globally and at subtelomeric regions. Interestingly, the level of MMSET-dependent H3K36me2 directly correlates with NHEJ-efficiency. We show that MMSET depletion does not impact on recognition of deprotected telomeres by the DDR-machinery or on subsequent recruitment of DDR-factors acting upstream or at the level of DNA repair pathway choice. Our data are most consistent with an important role for H3K36me2 in more downstream steps of the DNA repair process. Moreover, we find additional H3K36me2-specific HMTs to contribute to NHEJ at deprotected telomeres, further emphasizing the importance of $\mathrm{H} 3 \mathrm{~K} 36 \mathrm{me} 2$ in DNA repair.
\end{abstract}

\section{Introduction}

Efficient recognition and repair of DNA double-strand breaks (DSBs) are essential in maintaining genome integrity. Both occur in the context of the surrounding chromatin and are associated with specific chromatin alterations, including phosphorylation, ubiquitylation, methylation, and acetylation of histones that control recruitment of DNA damage responses (DDR)-proteins [1]. This is exemplified by 53BP1 binding to both dimethylated H4K20 (H4K20me2) and damage-induced H2AK15-ubiquitin to promote non-homologous end-joining (NHEJ)-mediated

Supplementary information The online version of this article (https:// doi.org/10.1038/s41388-020-1334-0) contains supplementary material, which is available to authorized users.

Jacqueline J. L. Jacobs

j.jacobs@nki.nl

1 Division of Oncogenomics, The Netherlands Cancer Institute, Plesmanlaan 121, 1066 CX Amsterdam, The Netherlands
DNA repair [2,3] and its counteraction by histone acetylation to shift toward repair by homologous recombination (HR) [4-6]. Finally, changes in chromatin compaction facilitate DSB repair, and different chromatin states impact on repair-efficiency, as seen by differences in repair-speed between heterochromatin and euchromatin $[1,7,8]$.

Telomeres are complex nucleoprotein structures that cap natural chromosome ends to protect them from being inadvertently recognized and processed as damaged DNA, thereby maintaining genome stability $[9,10]$. Telomeres are repetitive in nature and resemble heterochromatin by containing HP1, H3K9me3, H4K20me3, and low levels of H3and H4-acetylation [11, 12]. These marks are dynamic, as telomere repeat shortening decreases the repressive H3K9me3 and H4K20me3 marks and increases histone acetylation [13]. Telomere dysfunction due to extensive shortening of telomeric TTAGGG-repeat DNA, or functional loss of the telomere-specific protein complex shelterin, results in recognition of natural chromosome ends as DSBs. This triggers a damage response resembling the DDR at DNA DSBs [14]. It is initiated by MRN (MRE11/RAD50/ NBS1) and ATM and ATR kinases that by activating a DNA 
damage checkpoint force cells into apoptosis or senescence. Simultaneously, ATM-induced DDR signaling at uncapped telomeres recruits repair factors that through NHEJ cause chromosome end-to-end fusions [12, 15]. Also in telomere dysfunction chromatin plays important roles. For instance, inhibiting RNF8-mediated chromatin ubiquitylation, inhibiting the chromatin remodeler CHD2, or decreasing the heterochromatic state with HDAC-inhibitors or SUV39H1/2 depletion, impairs NHEJ at telomeres [16-19]. Also, depletion of Ring $1 \mathrm{~b}$, described to affect chromatin compaction, impairs telomere fusion [16].

Here, we identified the SET-domain containing histone methyltransferase (HMT) MMSET (multiple myeloma SET domain, a.k.a NSD2 or WHSC1), as a factor contributing to telomere-induced genomic instability. MMSET is deleted in human Wolf-Hirschhorn syndrome and dysregulated in multiple myeloma patients with a $\mathrm{t}(4 ; 14)$ translocation, in which the translocation-dependent overexpression of MMSET drives oncogenic transformation [20-25]. Moreover, MMSET mRNA and protein levels are increased in multiple cancers [26, 27]. Interestingly, MMSET has been implicated in the repair of DNA lesions caused by various DNA-damaging sources [28-30]. Here, we describe a novel role for MMSET in controlling DNA repair at telomeres. We find that MMSET promotes Ligase4-dependent c-NHEJ at uncapped telomeres and thereby genomic instability, in a manner directly correlating with its ability to catalyze H3K36-dimethylation (H3K36me2). Since upstream control of NHEJ by ATM-signaling and 53BP1-mediated inhibition of DNA end-resection were unaffected by MMSET depletion, we hypothesize that MMSET, through catalyzing $\mathrm{H} 3 \mathrm{~K} 36 \mathrm{me} 2$, affects the engagement or activity of factors acting downstream in NHEJ. Furthermore, we identified additional H3K36-methyltransferases that contribute to telomere-NHEJ. Altogether, this suggests an important role for $\mathrm{H} 3 \mathrm{~K} 36 \mathrm{me} 2$ in the processing of dysfunctional telomeres.

\section{Results}

\section{MMSET regulates telomere dysfunction-induced genomic instability}

To better understand how modification of chromatin affects recognition and processing of uncapped telomeres we set out to identify histone modifying enzymes that contribute to telomere-induced genomic instability. For this we used $\operatorname{Tr} 2^{-/-}$; $p 53^{-1-}$ mouse embryo fibroblasts (MEFs) containing a temperature-sensitive allele of the shelterin component TRF2 (TRF2 ${ }^{\text {Ile468Ala; }}$ TRF2ts) [31]. Culturing TRF2ts MEFs at nonpermissive temperatures $\left(37-39^{\circ} \mathrm{C}\right)$ causes TRF2 to dissociate from telomeres and recognition of telomeres as DNA DSBs.
This results in chromosome end-to-end fusions and severe chromosomal instability, causing cells to die of crisis or enter an irreversible growth arrest. Inhibiting factors critical in the end-joining of deprotected telomeres enables these cells to survive despite prolonged telomere uncapping, as we previously showed for Ligase4, RNF8, RNF168, and MAD2L2 [18, 32]. We selected 38 known or predicted methyltransferases and inhibited their expression using a short hairpin RNA (shRNA) library. TRF2ts MEFs were transduced with the library, cultured for 12 days at the nonpermissive temperature $\left(39^{\circ} \mathrm{C}\right)$ to induce telomere uncapping and returned to $32{ }^{\circ} \mathrm{C}$ to promote expansion of surviving cells (Fig. 1a). Interestingly, one shRNA-pool (pool 7) clearly rescued cell viability after prolonged telomere uncapping (Fig. 1b). Deconvolution of this shRNApool into single target gene pools identified the HMT Mmset as being responsible for the observed survival (Fig. 1c). Multiple independent shRNAs targeting Mmset rescued telomere dysfunction-induced lethality to an extent correlating with MMSET levels (Fig. 1d, Supplementary Fig. 1A). Indeed, cells depleted of MMSET continued proliferating despite telomere uncapping (Fig. 1e). Moreover, complementation of MMSET-depleted cells with expression of full-length MMSET cDNA abolished the rescue of cell proliferation in conditions of telomere uncapping (Fig. 1e, Supplementary Fig. 1B, C), showing that this effect is specific for MMSET. Importantly, Mmset knockdown did not affect cell cycle distribution (Supplementary Fig. 1D, E), excluding disturbed cell cycle kinetics as potential factor in escape from genomic crisis. Together, these results identify MMSET as a novel regulator of telomere dysfunction-induced genomic instability.

\section{MMSET facilitates c-NHEJ at uncapped telomeres}

Upon telomere uncapping, the activated DDR triggers NHEJ-mediated ligation of the deprotected chromosome ends at their telomeres [33]. To address whether MMSET functions in NHEJ at uncapped telomeres we inactivated TRF2-mediated telomere protection for $24 \mathrm{~h}$ in MMSETdepleted TRF2ts MEFs and analyzed the number of fused chromosomes using telomere fluorescence in-situ hybridization (FISH). Interestingly, MMSET-depleted cells showed a clear reduction in chromosome end fusions, of $\sim 40 \%$ (Fig. 2a-c). Also, MMSET-depleted wild-type MEFs transduced with an shRNA targeting $\operatorname{Trf} 2$ showed significantly reduced telomere fusion (Fig. 2d, e, Supplementary Fig. 2A). Telomeres terminate in G-rich $3^{\prime}$ single-stranded DNA (ssDNA) overhangs that are lost during NHEJ-mediated ligation [15, 34]. In line with their reduction in chromosome fusions, MMSET-depleted cells retained telomeric G-overhangs after $48 \mathrm{~h}$ of telomere uncapping (Fig. 2f, g). Moreover, aneuploidy caused by 

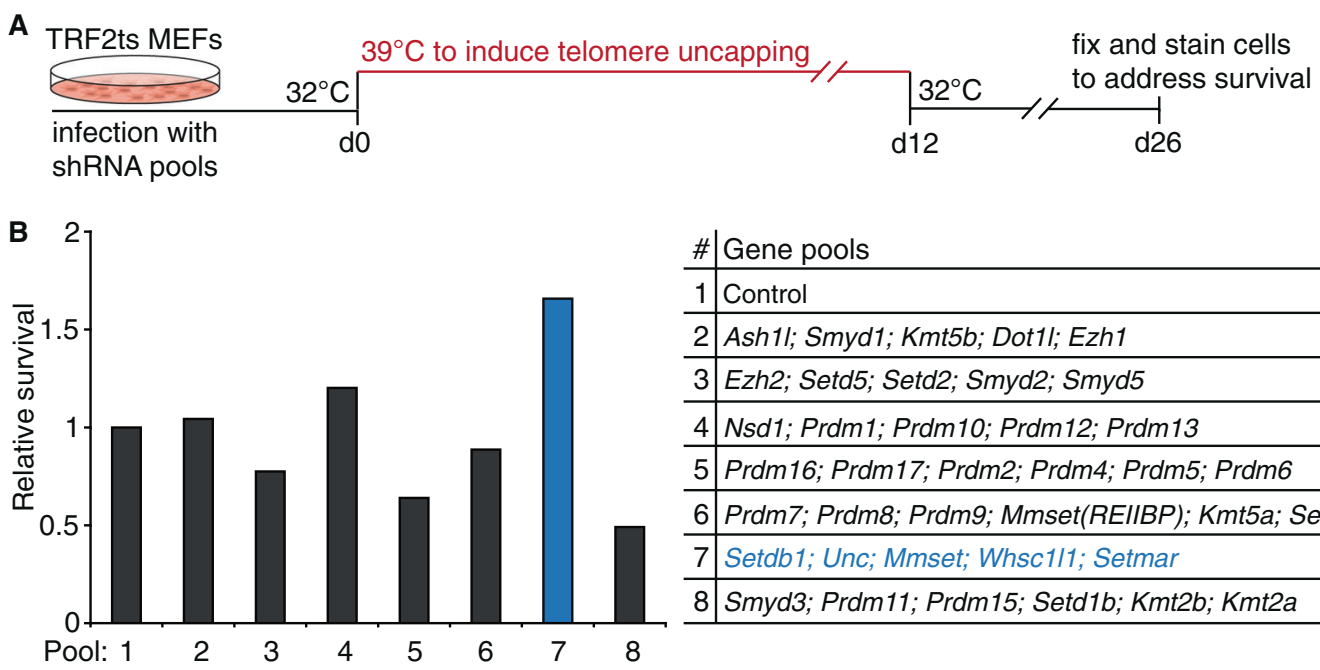

\begin{tabular}{r|l}
$\#$ & Gene pools \\
\hline 1 & Control \\
\hline 2 & Ash11; Smyd1; Kmt5b; Dot11; Ezh1 \\
\hline 3 & Ezh2; Setd5; Setd2; Smyd2; Smyd5 \\
\hline 4 & Nsd1; Prdm1; Prdm10; Prdm12; Prdm13 \\
\hline 5 & Prdm16; Prdm17; Prdm2; Prdm4; Prdm5; Prdm6 \\
\hline 6 & Prdm7; Prdm8; Prdm9; Mmset(REIIBP); Kmt5a; Setd7 \\
\hline 7 & Setdb1; Unc; Mmset; Whsc111; Setmar \\
\hline 8 & Smyd3; Prdm11; Prdm15; Setd1b; Kmt2b; Kmt2a \\
\hline
\end{tabular}
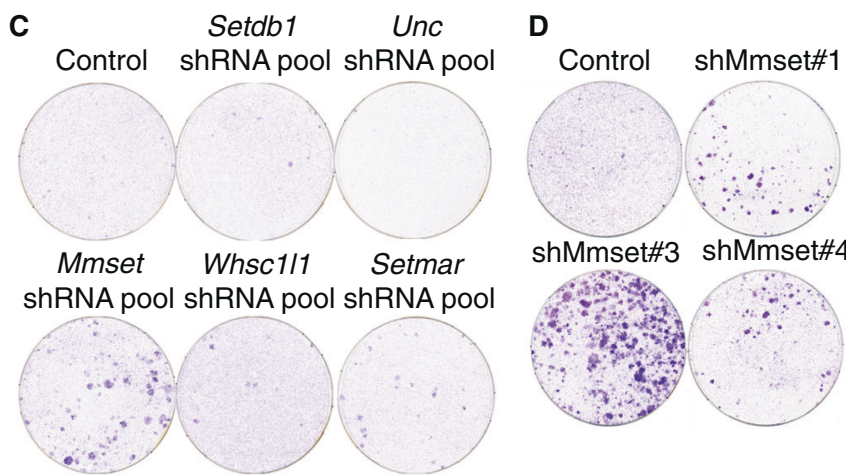

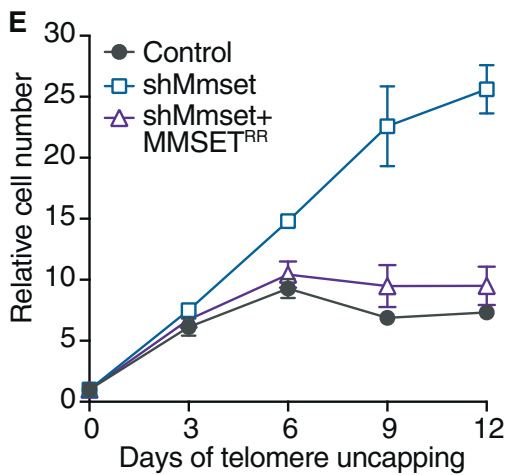

quantification. Survival in control infected cells was used as reference (=1). c Survival assay in TRF2ts MEFs with deconvoluted shRNApool 7 used in (b). d Survival assay in TRF2ts MEFs infected with individual shRNAs targeting Mmset. e Growth curves of control or MMSET-depleted TRF2ts MEFs complemented with control or shRNA-resistant (RR) Flag-tagged MMSET ${ }^{\mathrm{RR}}$ and grown at $39^{\circ} \mathrm{C}$ for the indicated days (data represent mean \pm s.d. of a technical triplicate). staining with crystal violet. b Relative survival of TRF2ts MEFs infected with the indicated shRNA target gene pools (Unc= uncharacterized). After staining, crystal violet was extracted for

missegregation of chromosomes that fused upon telomere uncapping, was partially alleviated in cells with reduced Mmset, as is also observed in cells deficient for c-NHEJ due to Ligase4 or Rnf8 inhibition (Supplementary Fig. 2B, C).

We next aimed to understand whether MMSET affects only telomere fusions generated through DNA ligase 4dependent c-NHEJ or also contributes to DNA ligase 3dependent alt-NHEJ. At unperturbed telomeres, the shelterin complex represses both c-NHEJ and alt-NHEJ. In addition, alt-NHEJ is repressed by $\mathrm{Ku} 70 / 80$ [33]. Upon TRF2 loss, the vast majority of telomere fusions are mediated through Ligase4-dependent c-NHEJ [34]. Indeed, chromosome end-to-end fusion after $24 \mathrm{~h}$ of TRF2 inactivation was strongly repressed in Ligase4-deficient TRF2ts MEFs, compared with Ligase4-proficient TRF2ts MEFs (25 to $3 \%$, Fig. 2a). The smaller percentage of fusions left result from Ligase4-independent alt-NHEJ. These were not further decreased by Mmset inhibition, suggesting that MMSET does not contribute to Ligase4-independent alt-NHEJ (Fig. 2a, c). To further address this, we used $\mathrm{TRF} 1^{\mathrm{F} / \mathrm{F}}$;

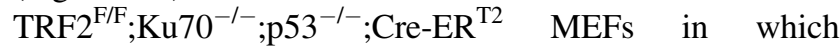
tamoxifen-induced loss of TRF1 and TRF2 causes processing of deprotected telomeres by Ligase3- and PARP1dependent alt-NHEJ [33]. Indeed, chromosomal fusions after 4 days tamoxifen treatment were significantly reduced upon PARP1 inhibition with Olaparib (Fig. 2h). Conversely, Mmset depletion (Supplementary Fig. 2D, E) did not reduce these alt-NHEJ mediated chromosomal fusions (Fig. 2h). Likewise, shRNA-mediated inhibition of Ligase 3 or Parpl, but not Mmset, significantly reduced

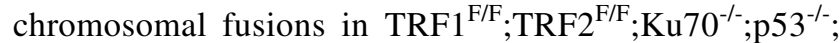
Cre-ER ${ }^{\mathrm{T} 2}$ MEFs treated with tamoxifen for 5 days (Supplementary Fig. 2F, G). Thus, MMSET does not affect 
A

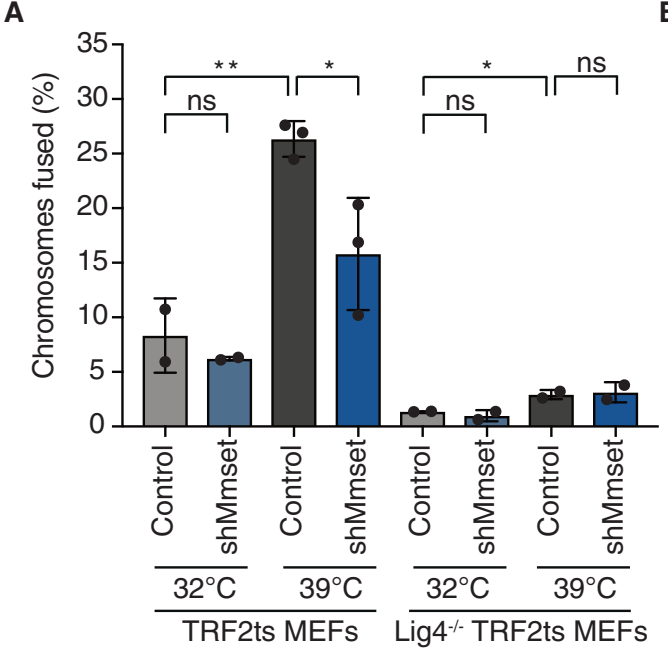

B

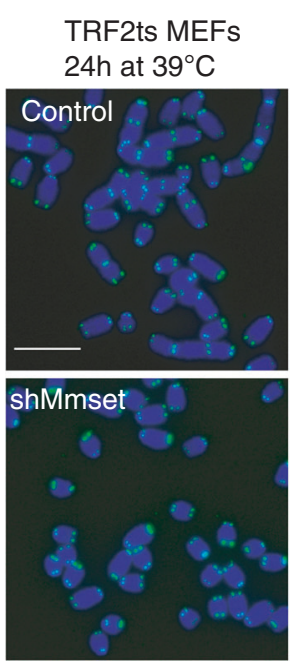

F

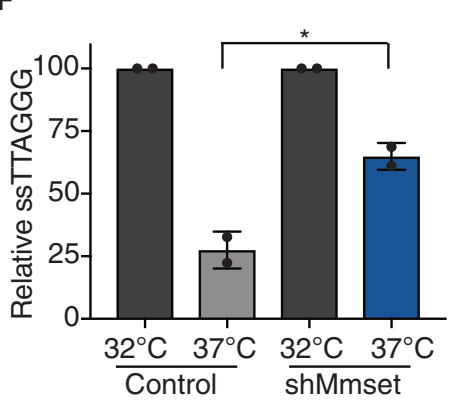

G

shMmset: $\frac{32}{-++}$

$\operatorname{Mr}(\mathrm{K})$
145
97

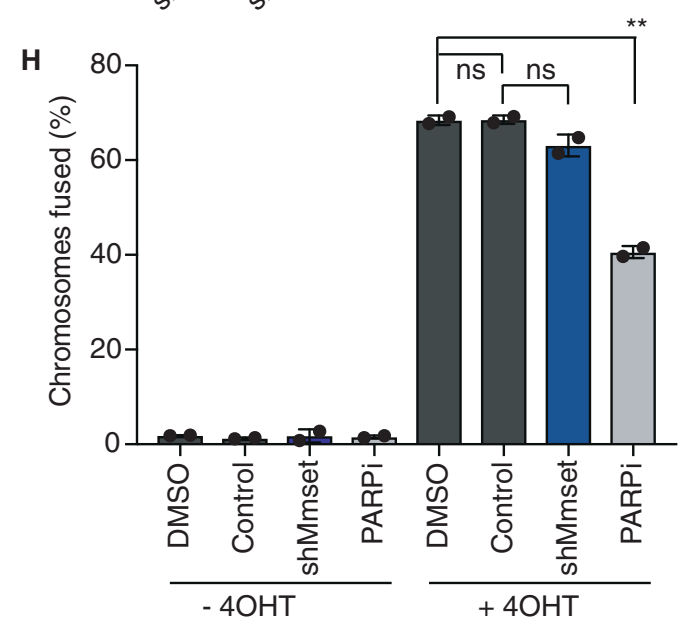

Fig. 2 MMSET induces NHEJ-mediated telomere fusion and Goverhang degradation. a Chromosome fusions in TRF2ts MEFs and LigIV $^{-1-}$ TRF2ts MEFs transduced with control or Mmset-targeting shRNA ( $n=2-3$ independent experiments, mean \pm s.d., unpaired $t$ test: ns, not significant; $\left.{ }^{*} p \leq 0.05\right)$. b Representative metaphase spreads of TRF2ts MEFs transduced as indicated, collected after $24 \mathrm{~h}$ at $39^{\circ} \mathrm{C}$ for telomere-FISH. Scale bar, $10 \mu \mathrm{m}$. c Immunoblot of TRF2ts MEFs or LigIV $^{-1-}$ TRF2ts MEFs used in (a), $\gamma$ tubulin serves as loading control. d Immunoblot of MMSET and H3K36me2 levels in MEFs used in (e). e Chromosomal fusions in wild-type (WT) MEFs transduced with control or Mmset-targeting shRNA prior to treatment with control or Trf2-targeting shRNA for 5 days to induce telomere uncapping. Control transduced $53 \mathrm{bpl}^{-1-}$ and Rif $1^{-1-}$ MEFs were included for comparison. Values were normalized for the control condition $(n=2$ independent

$$
\text { G }
$$

ssTTAGGG Total TTAGGG $\overline{\frac{32^{\circ} \mathrm{C}}{-+} \frac{37^{\circ} \mathrm{C}}{-+}}$
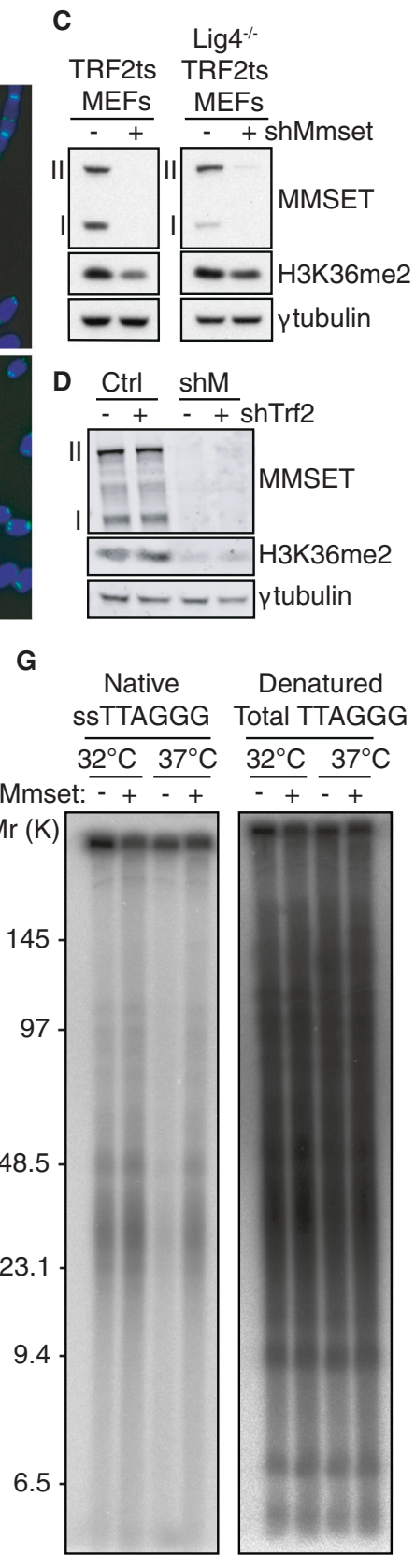
overhang quantification $(n=2$ independent experiments, mean \pm s.d., unpaired $t$ test: $* p \leq 0.05$ ). g Representative telomeric G-overhang assay in control and Mmset knockdown TRF2ts MEFs after $48 \mathrm{~h}$ at the nonpermissive temperature $\left(37^{\circ} \mathrm{C}\right)$. h Chromosome fusions in TRF1 ${ }^{\mathrm{F}}$ ${ }^{\mathrm{F}} \mathrm{TRF} 2^{\mathrm{F} / \mathrm{F}} \mathrm{Ku} 70^{-l-} \mathrm{p} 53^{-l-}$ MEFs treated with DMSO or PARPi (Ola$(+4 \mathrm{OHT})$ was counted per condition per individual experiment. Genexperiments, mean \pm s.d., unpaired $t$ test: ns, not significant; $* * p \leq 0.01$ ).

experiments, mean \pm s.d., unpaired $t$ test: $* * p \leq 0.01)$. f Telomeric Gparib, $0.5 \mu \mathrm{M})$, or transduced with control virus or shRNA targeting Mmset. Cells were treated with tamoxifen (4-OHT) for $24 \mathrm{~h}$ to induce deletion of floxed shelterin alleles and harvested after a total of 4 days. A minimum of 1500 chromosomes (-4OHT) or 2000 chromosomes otypes were blinded before manual scoring $(n=2$ independent 
alt-NHEJ at deprotected telomeres. Altogether, our results indicate that MMSET facilitates telomeric $3^{\prime}$ overhang degradation and telomere fusion through Ligase4dependent c-NHEJ, and contributes to telomere dysfunction-induced aneuploidy.

\section{MMSET promotes H3K36-dimethylation globally and at subtelomeres}

MMSET is a SET-domain containing HMT. Despite conflicting reports on its catalytic activity, its primary activity appears to be H3K36 mono- and dimethylation [22, 24, 35]. Indeed, Mmset depletion caused consistent reduction of global H3K36-dimethylation (H3K36me2) (Fig. 2c, d, Supplementary Fig. 2D), in line with previous reports $[24,30,36,37]$. This decrease was observed both in absence and presence of telomere uncapping, or DNA damage induced by irradiation (IR), and restored by expressing shRNA-resistant full-length MMSET (Fig. 3a-c, Supplementary Fig. 3A, B). Of note, global levels of H4K20-dimethylation, H3K9-trimethylation or H3K36acetylation were unaffected (Fig. 3a, Supplementary Fig. 1B). In addition, in both MMSET-depleted MEFs and Mmset-knockout MEFs H3K36-monomethylation (H3K36me1) was decreased and, in line with previous studies, also H3K36-trimethylation (H3K36me3, Fig. 3a, Supplementary Fig. 3A, B) [22, 36]. Since H3K36me3 is exclusively catalyzed by SETD2/HYPB [38, 39], we hypothesize that the reduced H3K36me3 upon MMSET loss might be a consequence of less H3K36me2 substrate being available for SETD2-mediated trimethylation.

To understand whether the H3K36me2 decrease in MMSET-depleted cells also occurs at (sub)telomeric regions, we performed chromatin immunoprecipitation (ChIP) experiments with histone $\mathrm{H} 3$ and H3K36me2 antibodies, followed by quantitative real-time PCR (qRTPCR) for subtelomeric regions on chromosome 1, 16, or 19 , or a GAPDH control region. Interestingly, in MMSET-depleted cells H3K36me2 was significantly reduced at all three subtelomeric regions (Fig. 3d, Supplementary Fig. 3C). This indicates that the global reduction in H3K36me2 in the absence of MMSET also affects H3K36me2 at (sub)telomeric regions and we hypothesize that by doing so it impacts on DNA repair at deprotected telomeres. Although for reasons of assay sensitivity we cannot exclude a very local or subtle change in H3K36me 2 close to the telomere end, we could not detect an increase in $\mathrm{H} 3 \mathrm{~K} 36 \mathrm{me} 2$ at (sub)telomeric regions upon telomere deprotection (Supplementary Fig. 3D). In line with this, we detected limited association of MMSET with telomeres by ChIP, that was not detectably enhanced upon $3 \mathrm{~h}$ of telomere uncapping (Supplementary Fig. 3E, F).

\section{H3K36-dimethylation by MMSET correlates with NHEJ-efficiency}

We next asked whether the H3K36-methyltransferase activity of MMSET, enabled by its SET domain, is important for MMSET activity in promoting telomere fusions. We generated shRNA-resistant mutant versions of MMSET, confirmed their expression and tested their ability to promote genomic crisis in TRF2ts cells depleted for endogenous MMSET (Fig. 3e-g). Exogenous full-length wild-type MMSET abolished the survival of MMSETdepleted TRF2ts MEFs subjected to prolonged telomere uncapping, as seen before in growth curves (Fig. 1e). Interestingly, a catalytically inactive MMSET (SET-domain mutant, H1143 G [22]) and a mutant MMSET lacking its PHD (plant homeodomain) zinc finger domain, important for binding methylated residues [38], were both unable to abolish survival of MMSET-depleted cells. This indicates that the methyltransferase activity as well as the PHD domain are essential for MMSET to promote telomere-NHEJ. On the contrary, the N-terminal PWWP (Pro-Trp-Trp-Pro) chromatin-interacting domain [38] and HMG (high-mobility group) domain are dispensable for MMSET function in promoting genomic crisis upon telomere uncapping, as cells expressing MMSET mutants lacking these domains ( $\triangle$ PWWP or $\triangle \mathrm{HMG)} \mathrm{efficiently} \mathrm{arrested} \mathrm{and} \mathrm{died} \mathrm{upon} \mathrm{tel-}$ omere uncapping. Indeed, the PWWP and HMG domain mutants of MMSET efficiently restored NHEJ-mediated telomere fusion in MMSET-depleted cells, whereas the H1143G and PHD domain mutants did not (Supplementary Fig. 3G).

To further address whether the observed cellular responses to telomere uncapping correlated with H3K36me2 levels, we assessed H3K36me2 levels in histone fractions of MMSETdepleted cells complemented with the various MMSET expression constructs (Fig. 3h). Again, the decrease in H3K36me2 in MMSET-depleted cells was rescued by exogenous wild-type MMSET. Interestingly, both the SETmutant and PHD-truncated form $(\triangle \mathrm{PHD})$ were unable to restore $\mathrm{H} 3 \mathrm{~K} 36 \mathrm{me} 2$ levels, while expression of the $\triangle \mathrm{PWWP}$ or $\triangle$ HMG MMSET mutants restored or even enhanced H3K36me2. Thus, the ability of the different MMSET mutants to restore H3K36me2 levels directly correlates with their effect on cell survival and chromosomal fusions after telomere uncapping. Although we cannot exclude potential additional activities, this suggests that MMSET facilitates cNHEJ at deprotected telomeres by promoting H3K36me2 through its SET and PHD domains.

\section{MMSET is dispensable for early DDR signaling at uncapped telomeres}

As both MMSET and H3K36-methylation have been associated with transcriptional control [22], we first 


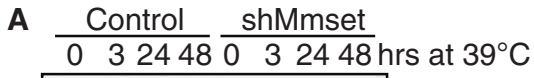

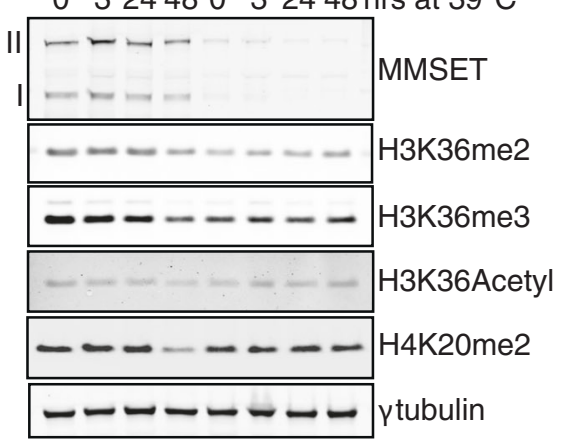

B - + + MMSETRR

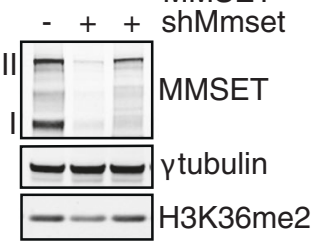

C Control shMmset

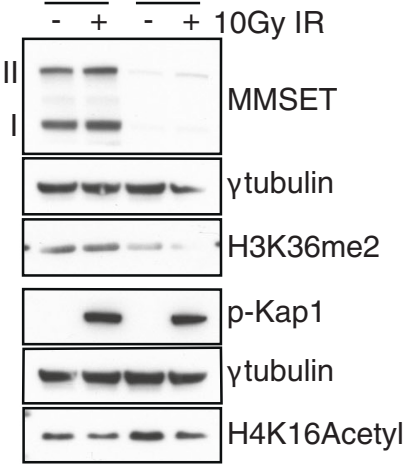

D

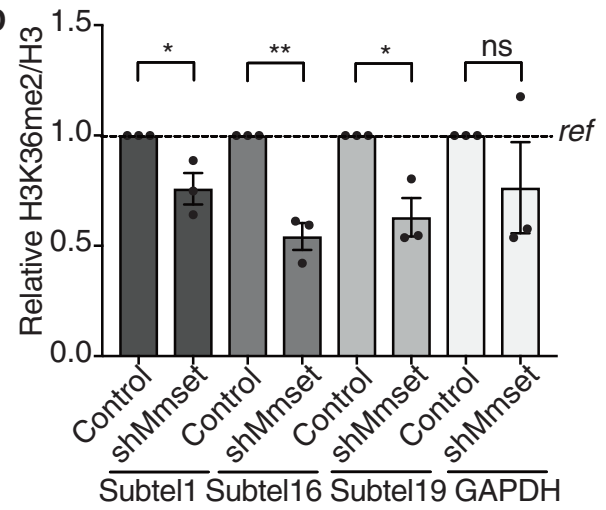

E

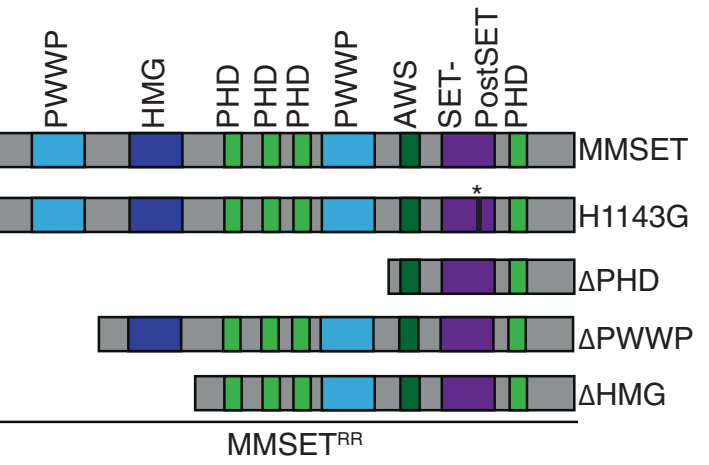

$\mathbf{F}$

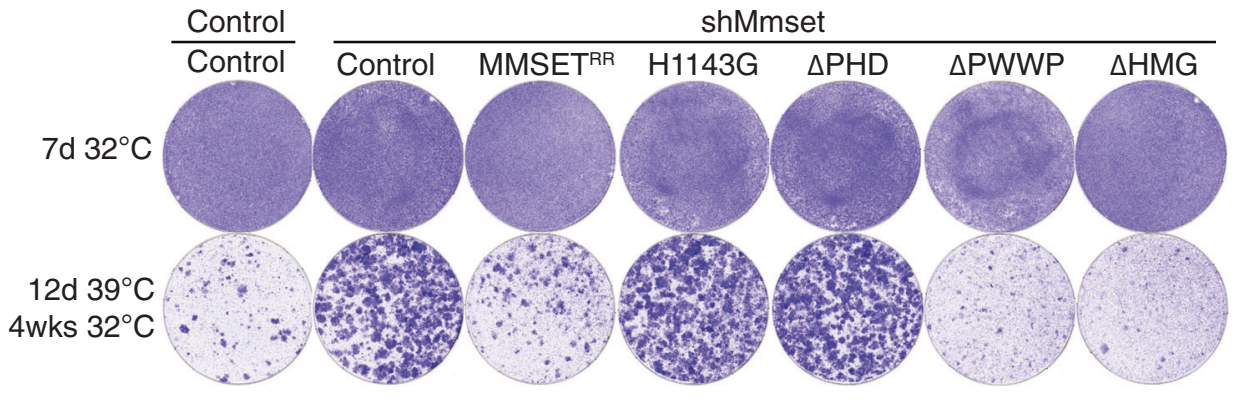

G

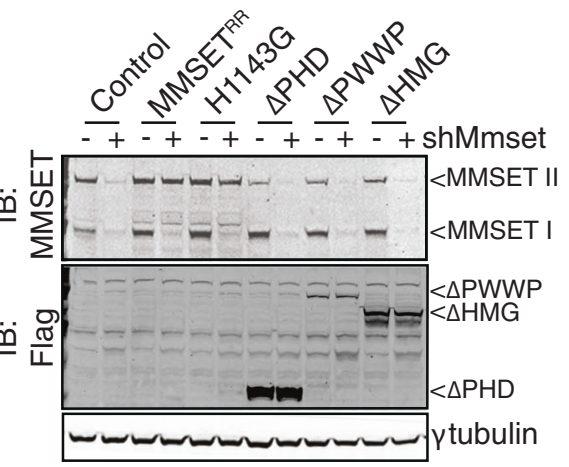

H

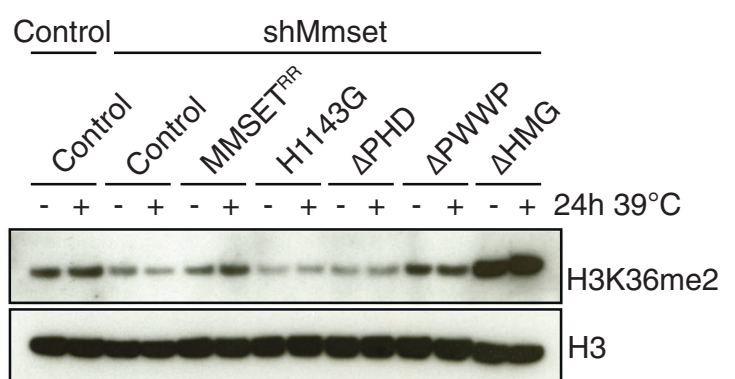

considered that MMSET might indirectly affect telomereNHEJ through transcriptional regulation of DDR-factors. However, MMSET depletion did not significantly affect mRNA levels of various DDR-factors tested, including factors known to be important for telomere-NHEJ, like RNF8, RNF168, 53BP1, MAD2L2, LIG4 (DNA ligase 4), and XRCC4 (Supplementary Fig. 4A, B). In addition, MMSET depletion did not affect RAD51, 53BP1 and LIG4 protein levels (Fig. 4a, Supplementary Fig. 4C, D). Although we cannot exclude minor effects or effects through transcriptional regulation of genes not addressed, these results supported examination of other potential ways 
Fig. 3 MMSET promotes NHEJ of uncapped telomeres through H3K36 dimethylation. a Immunoblot of histone marks in TRF2ts MEFs transduced as indicated and kept at $39{ }^{\circ} \mathrm{C}$ for indicated times to induce telomere uncapping. $\gamma$ tubulin serves as loading control. b Immunoblot for H3K36me2 in TRF2ts MEFs transduced as indicated and used in Fig. 1e and Supplementary Fig. 1c, in the absence of telomere damage $\left(32^{\circ} \mathrm{C}\right)$. c Immunoblot of $\mathrm{p} 53^{-/-}$MEFs transduced as indicated, untreated or $20 \mathrm{~min}$ post IR ( $10 \mathrm{~Gy})$. $\gamma$ tubulin serves as loading control. d Relative enrichment of $\mathrm{H} 3 \mathrm{~K} 36 \mathrm{me} 2 / \mathrm{H} 3$ for the indicated target regions in control or shMmset transduced TRF2ts MEFs cultured for $3 \mathrm{~h}$ at $39^{\circ} \mathrm{C}$, determined by ChIP for $\mathrm{H} 3$ and H3K36me2 and qRT-PCR. QRT-PCRs of individual experiments were performed in technical triplicates and normalized to input DNA. H3K36me2 ChIP data was then normalized for total $\mathrm{H} 3$ ( $n=3$ independent ChIP experiments, mean $\pm \mathrm{SEM}$, unpaired $t$ test: ns, not significant; $* p \leq 0.05 ; * * \leq 0.01)$. e Schematic representation of different MMSET cDNA constructs used. H1143G, SET-domain mutant; PHD, plant homeodomain; PWWP, Pro-Trp-Trp-Pro motif; HMG, high mobility-group motif; MMSET ${ }^{\mathrm{RR}}$, RNAi-resistant (RR) MMSET. f Survival assay of TRF2ts MEFs transduced with indicated shRNA and cDNA constructs and cultured as specified (representative of $n=2$ independent experiments). $g$ Immunoblot showing expression of the different MMSET cDNA constructs. The upper blot, probed with MMSET antibody, shows both full-length MMSET isoform II containing the catalytic domain and the smaller MMSET isoform I that lacks catalytic activity. Both isoforms are targeted by the Mmset shRNA used, while complementation with RNAi-resistant full-length MMSET cDNA (wild-type or H1143G mutant) only restores fulllength MMSET isoform II expression. The PHD, PWWP and HMG truncated MMSET variants lose the MMSET antibody epitope and are detected by a Flag-antibody in de lower blot. h Immunoblot for $\mathrm{H} 3 \mathrm{~K} 36 \mathrm{me} 2$ in histone extracts of TRF2ts MEFs transduced as indicated and cultured at $32{ }^{\circ} \mathrm{C}$ or for $24 \mathrm{~h}$ at $39^{\circ} \mathrm{C}$. H3 serves as loading control (representative of 2 independent experiments).

by which MMSET might affect NHEJ at telomeres. We therefore addressed the activation of DNA damage signaling responses. While MMSET-depleted TRF2ts MEFs showed decreased $\mathrm{H} 3 \mathrm{~K} 36 \mathrm{me} 2$ prior to and during telomere uncapping, phosphorylation of KAP1, H2AX, or CHK2 at 3 or $24 \mathrm{~h}$ of telomere deprotection was unaffected by MMSET depletion (Fig. 4a). We interpret the slightly higher KAP1 and H2AX phosphorylation in MMSET-depleted cells at $48 \mathrm{~h}$ of telomere uncapping as a consequence of reduced repair by NHEJ, while in control cells DNA damage signaling declines upon telomere-NHEJ. Also IR-induced KAP1, H2AX, and CHK2 phosphorylation were similar in control and MMSET-depleted cells (Supplementary Fig. 4E). We also analyzed subnuclear foci of H2AX phospho-S139 ( $\gamma \mathrm{H} 2 \mathrm{AX})$, ATM phospho-S1981 (p-ATM), and conjugated ubiquitin that spreads over chromatin surrounding sites of DNA damage and is detectable with FK2 antibody [40]. Telomere deprotection for $3 \mathrm{~h}$ led to clear accumulation of $\gamma \mathrm{H} 2 \mathrm{AX}$, p-ATM, and FK2 signal into foci, that were not different in number between MMSET-depleted cells and control cells (Fig. 4b-e, Supplementary Fig. 4F). Together these results indicate that MMSET does not impact on the recognition of uncapped telomeres and early signaling responses by the DDRmachinery.

Downstream of these early DDR responses is the control of DNA repair pathway choice by 53BP1 and BRCA1, in which 53BP1 inhibits DNA end-resection to facilitate NHEJ while BRCA1 promotes end-resection to generate $3^{\prime}$ ssDNA-overhangs and direct DNA repair by HR [32, 33, 41-47]. MMSET has been implicated in the recruitment of 53BP1 to DNA damage via induction of H4K20me2 [28, 29]. However, additional reports showed that MMSET does not have specific activity toward H4K20me2 and does not affect 53BP1 recruitment [5, 48, 49]. In line with the latter reports, we did not observe defects in 53BP1 recruitment and accumulation at deprotected telomeres in MMSET-depleted cells by immunofluorescence (IF), or IF-FISH (Fig. 4b, c, Supplementary Fig. 4F, G). Furthermore, global H4K20me2 levels appeared unaffected by MMSET depletion (Fig. 3a). We next investigated if MMSET affects ssDNA formation. Phosphorylation of CHK1 was slightly increased in MMSET-depleted cells, which may indicate increased ATR activation (Supplementary Fig. 5A). However, we did not observe increased phosphorylation of the ssDNAbinding protein RPA upon IR or telomere deprotection (Supplementary Fig. 5A, B), as would be seen upon loss of the end-resection inhibitors 53BP1, RIF1 or MAD2L2 [32, 42, 44]. Also, recruitment of BRCA1 to uncapped telomeres was not significantly altered (Supplementary Fig. 5C, D). Together this suggests that MMSET depletion does not impair NHEJ by enhancing end-resection and ssDNA formation.

As upstream DDR responses are unperturbed in MMSET-depleted cells, we consider it most likely that MMSET affects engagement or activity of the NHEJmachinery itself. We therefore analyzed the effect of MMSET depletion on DNA-PKcs autophosphorylated on S2056 (p-DNA-PKcs), important for the ligation of DNA ends during NHEJ $[50,51]$. Telomere deprotection for $3 \mathrm{~h}$ led to clear accumulation of p-DNA-PKcs subnuclear foci that were not different in number between MMSETdepleted cells and control cells, indicating that NHEJ is not affected by MMSET at the level of DNA-PKcs localization and autophosphorylation (Fig. 4b, c, Supplementary Fig. 4F). Other NHEJ-components do not accumulate robustly enough at telomeres to be detected as clearly discernable foci by IF. We therefore aimed to further address telomeric localization of NHEJ-components by ChIP. As MMSET was previously connected to the recruitment of XRCC4 to DNA damage [30], we attempted to assess telomeric-localization of XRCC4 by ChIP, using either qRT-PCR with subtelomere-specific primers or dot blot detection of TTAGGG-telomere repeats. However, the signals retrieved for XRCC4-ChIP at (sub)telomeres were 
Fig. 4 MMSET does not affect DNA damage signaling at unprotected telomeres. a Immunoblots of different DDRfactors in TRF2ts MEFs, control infected or transduced with an shRNA targeting Mmset and subjected to telomere uncapping at $39{ }^{\circ} \mathrm{C}$ for the indicated times. ytubulin, $\beta$-actin, and $\mathrm{H} 3$ serve as loading controls (representative blots of a minimum of two independent experiments). b Quantification of 53BP1 foci, p-ATM foci, $\gamma \mathrm{H} 2 \mathrm{AX}$ foci, and p-DNA-PKcs foci in TRF2ts MEFs in undamaged conditions $\left(32^{\circ} \mathrm{C}\right.$; $0 \mathrm{~h}$ ) or after $3 \mathrm{~h}$ of telomere deprotection $\left(39^{\circ} \mathrm{C} ; 3 \mathrm{~h}\right) .(n=4$ independent experiments, mean \pm SEM, a minimum of 312 (53BP1), 316 (p-ATM), or 158 $(\gamma \mathrm{H} 2 \mathrm{AX})$ cells were quantified in each condition and per experiment; $n=2$ for p-DNA$\mathrm{PKcs}$, mean \pm s.d., a minimum of 81 cells per condition per experiment). c Representative images of foci quantified in (b). Scale bars, $10 \mu \mathrm{m}$. d Quantification of FK2 foci in TRF2ts MEFs transduced with an shRNA targeting Mmset or control, and placed at the nonpermissive temperature of $39^{\circ} \mathrm{C}$ for 3 or $16 \mathrm{~h}$ to induce telomere uncapping. In each experiment a minimum of 178 cells were quantified per condition $(n=2$ independent experiments, mean \pm s.d.). $\mathbf{e}$ Representative images of cells quantified in (d). Scale bar, $10 \mu \mathrm{m}$.
A

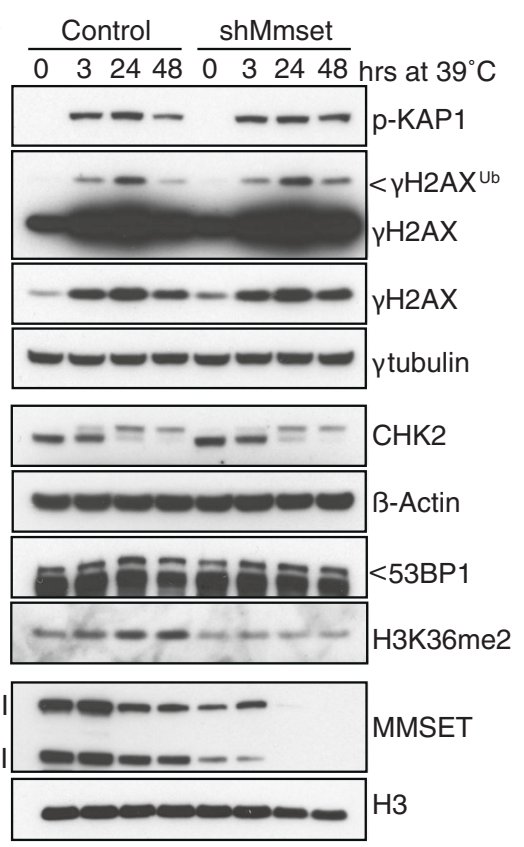

B
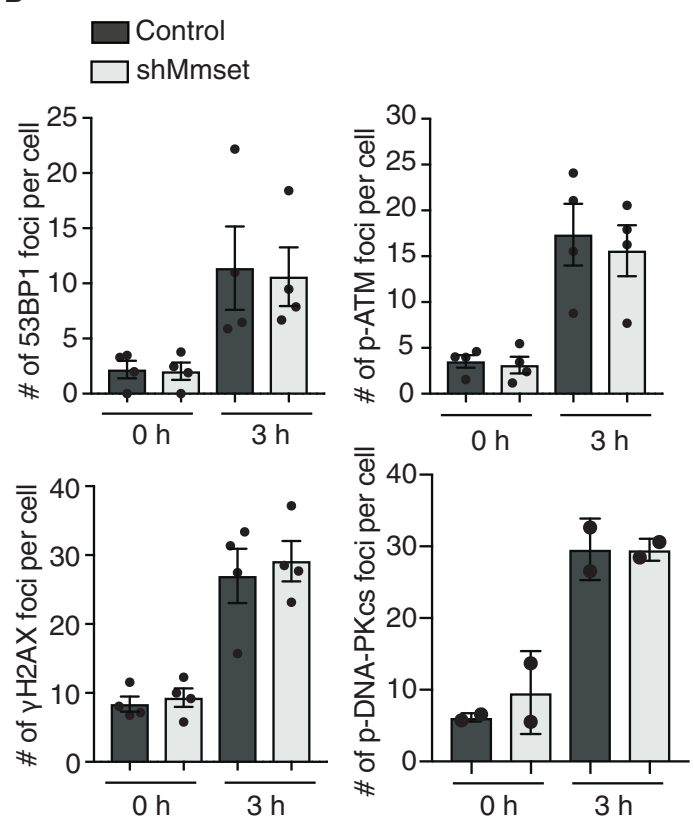

C

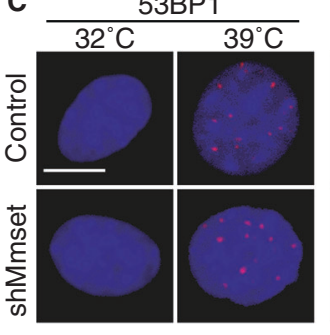

D

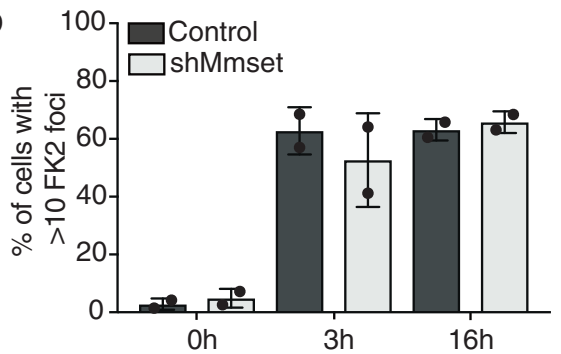

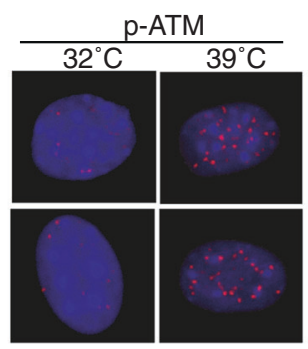
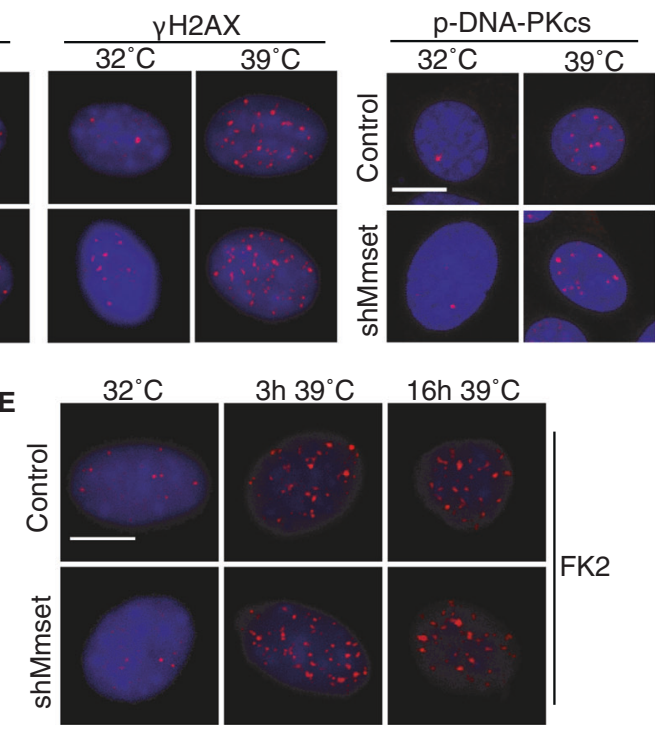

too low and not detectably increased upon telomere deprotection, precluding proper assessment of the potential effect of MMSET on XRCC4 localization to uncapped telomeres. This probably relates at least in part to the long 30-100 kb telomere-repeat stretches at mouse telomeres that complicate assessment of NHEJ-factors acting at telomere ends and not spreading extensively over telomeres, by ChIP. Therefore, although our data are most compatible with MMSET-dependent H3K36me2 being important for downstream steps in NHEJ at telomeres, such as those immediately preceding or at the actual DNA ligation step by the XRCC4/Lig4-complex, the precise mechanism remains unclear at this point.

\section{Additional H3K36me2-specific HMTs contribute to NHEJ at uncapped telomeres}

In mammalian cells, multiple SET-domain containing enzymes can catalyze H3K36me1 and H3K36me2 [38]. To address whether additional H3K36me2-specific HMTs affect NHEJ at telomeres we made shRNA-pools against the following HMTs: [38] Nsdl (9 shRNAs in 2 pools), Ash1l, Setmar, Smyd2, Setd3 (for each 4-5 shRNAs/pool), and Whscll1 (1 shRNA). These shRNA-pools were tested for enabling TRF2ts MEFs to avoid telomere NHEJrelated genomic crisis. Interestingly, inhibition of Setmar or Smyd2 with shRNA-pools gave TRF2ts cells a survival 

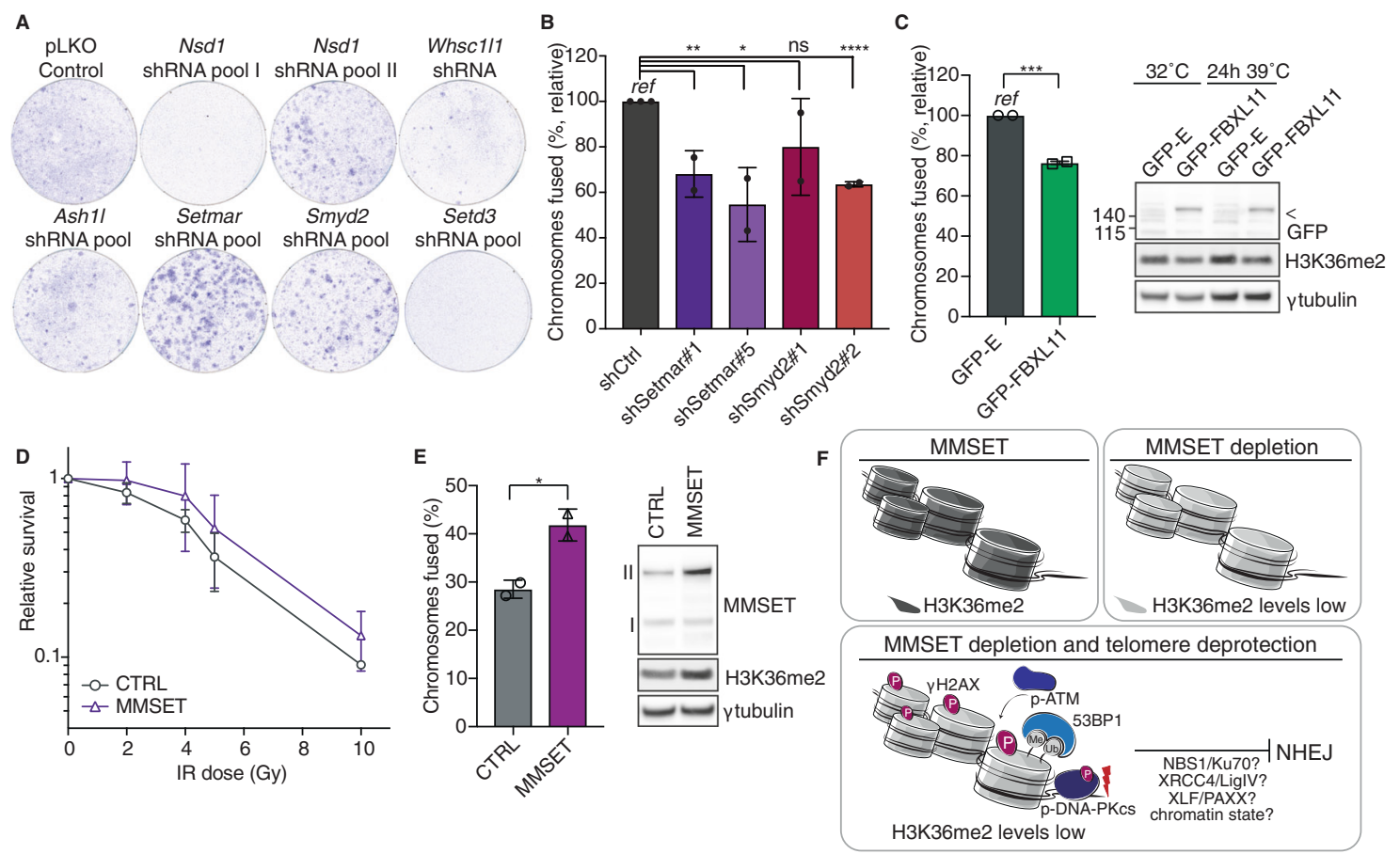

Fig. 5 Additional H3K36me2-specific HMTs contribute to NHEJ at uncapped telomeres. a Survival assay of TRF2ts cells transduced with the indicated lentiviral shRNA-pools or pLKO control vector. After 12 days at $39^{\circ} \mathrm{C}$ cells were returned to $32^{\circ} \mathrm{C}$ for 4 weeks and stained with crystal violet. b Chromosome fusions in TRF2ts MEFs transduced with indicated lentiviral shRNAs ('shCtrl': scrambled or luciferase control shRNA). A minimum of 1470 chromosomes was counted per condition per experiment and counts were normalized to shCtrl ( $r e f)(n=2$ independent experiments (except shCtrl, $n=3$ ), mean \pm s.d., unpaired $t$ test: $n s$, not significant; $* p \leq 0.05$; $* * \leq 0.01$; $* * * * p \leq 0.0001)$. c Left: chromosomal fusions upon $24 \mathrm{~h}$ of telomere uncapping at $39^{\circ} \mathrm{C}$ in TRF2ts MEFs transduced with GFP-tagged FBXL11 or GFP-expressing control vector ("GFP-E"). A minimum of 1800 chromosomes was counted per condition per experiment $(n=2$ independent experiments, mean \pm s.d., unpaired $t$ test: $* * * p \leq 0.001)$. Right: corresponding immunoblot for GFP-FBXL11 (arrow) and H3K36me2, ytubulin serves as loading control. d Relative survival of TRF2ts MEFs transduced with a MMSET expression ("MMSET") or empty ("CTRL") viral vector. Cells were irradiated with the indicated doses (Gy) and left to recover for 10 days prior to crystal violet staining and quantification $(n=2$, mean \pm s.d., cells were plated as technical duplicate). e Left: chromosomal fusions in TRF2ts MEFs transduced as in (d). A minimum of 2000 chromosomes was counted per condition per experiment $(n=2$ independent experiments, mean \pm s.d., unpaired $t$ test: $* p \leq 0.05)$. Right: corresponding immunoblot for MMSET and H3K36me2, $\gamma$ tubulin serves as loading control. f Model on how MMSET could affect NHEJ at telomeres through H3K36me2. benefit under telomere uncapping conditions (Fig. 5a). Moreover, depleting Setmar or Smyd2 using individual shRNAs decreased fusion of uncapped telomeres (Fig. 5b), indicating that also SETMAR and SMYD2 act in facilitating telomere-NHEJ. In fact, SETMAR has been implicated before in NHEJ in a different setting, indicating a more general role in NHEJ [52]. The identification of additional H3K36me2-specific HMTs that contribute to NHEJ at uncapped telomeres further emphasizes the importance of this chromatin modification in DNA repair and suggests that a certain degree of redundancy is at play.

Several lysine demethylases act in removing H3K36me2. We hypothesized that overexpressing such a H3K36me2specific lysine demethylase would mimic MMSET depletion. Indeed, overexpression of the H3K36me2-specific demethylase FBXL11 (a.k.a KDM2A or JHDM1A [53]) decreased fusion of uncapped telomeres in TRF2ts MEFs, further confirming the importance of H3K36me2 in telomere-NHEJ (Fig. 5c).

Finally, while compromised NHEJ due to lack of MMSET might sensitize cells to different types of DNA damage [28, 29], we hypothesized that cells expressing higher MMSET levels might have enhanced NHEJ capabilities, allowing them to cope better with IR-induced DNA damage. Indeed, MMSET overexpression made cells more resistant to IR (Fig. 5d), in line with recent work showing that MMSET-high $(\mathrm{t} 4 ; 14)+$ myeloma cells proliferate better upon treatment with DNA-damaging drugs than cells expressing wild-type MMSET levels [30]. Moreover, overexpression of MMSET in TRF2ts MEFs raised $\mathrm{H} 3 \mathrm{~K} 36 \mathrm{me} 2$ levels and increased telomere-NHEJ (Fig. 5e), further indicating that elevated MMSET levels enhance NHEJ-mediated DNA repair. 


\section{Discussion}

Here, we describe an important role for MMSET in facilitating c-NHEJ at deprotected telomeres. Our data suggest a role for MMSET-dependent H3K36me2 at late stages of the NHEJ process, downstream of 53BP1-controlled DNA repair pathway choice and independent of DNA-PKcs localization and autophosphorylation (Fig. 5f). MMSET has been implicated in DNA repair before. MMSETdepleted cells display impaired DNA repair in different cellular assays and increased sensitivity toward multiple DNA-damaging agents [28-30, 54, 55]. Although this points at a global role of MMSET in DNA repair, to what extent these phenotypes can be attributed specifically to NHEJ is not well established and also the underlying mechanism has been under debate. MMSET has been implicated in immunoglobulin class-switch recombination (CSR), a physiological process relying on c-NHEJmediated joining of induced DSBs [54, 55]. However, this seems largely attributable to MMSET affecting the generation of DSBs during CSR, rather than their endjoining. Furthermore, MMSET was reported to facilitate 53BP1 recruitment through de novo H4K20-dimethylation, thereby promoting 53BP1-directed repair [28, 29]. However, additional work indicated that the primary enzymatic activity of MMSET is toward H3K36, rather than H4K20, and that MMSET is dispensable for 53BP1 recruitment to DNA damage [5, 22, 24, 35, 36, 48, 49]. Our study is in line with the latter reports, as 53BP1 accumulation to uncapped telomeres was not affected by MMSET depletion, nor was end-resection detectably elevated, indicating that 53BP1's activity in inhibiting end-resection is preserved. Also, complementation assays with MMSET mutants showed that regulation of telomere-NHEJ by MMSET correlates directly with its effect on H3K36me2. Via H3K63me2, MMSET might promote telomere-NHEJ in multiple potential ways.

First, MMSET might indirectly facilitate NHEJ, in which changes in global H3K36me2 levels or the presence of MMSET itself affect transcriptional regulation of DDRproteins. Indeed, MMSET isoforms were shown to function in transcriptional regulation and interact with HDAC1 and HDAC2 transcriptional corepressors [22, 56-58]. Furthermore, MMSET overexpression in $\mathrm{t}(4 ; 14)+$ multiple myeloma cells changes the genomic distribution of H3K36me2 and affects gene expression [24, 36, 59]. While our data do not exclude that MMSET affects NHEJ through transcriptional regulation, we did not observe significant impact of MMSET depletion on the levels of various DDR-proteins critical in NHEJ or on activation and recruitment of p-ATM, $\gamma \mathrm{H} 2 \mathrm{AX}, 53 \mathrm{BP} 1$, BRCA1, and p-DNA-PKcs (Fig. 4). Thus, if there would be any effect by MMSET on NHEJ through transcriptional changes, this would most likely be relevant to steps further downstream or potential alternative mechanisms in DNA repair control.

Second, H3K36me2 could function as platform for DNA repair protein recruitment. H3K36 methylation has been linked to different DNA repair pathways. While SETD2dependent $\mathrm{H} 3 \mathrm{~K} 36 \mathrm{me} 3$ pre-exists and is highly enriched at actively transcribed genes where it channels DNA repair through HR [39, 60-62], H3K36me2 has been associated with NHEJ [52, 63-65]. H3K36me2 induced around DSBs by SETMAR (a.k.a. Metnase) promotes association and stabilization of Ku70 and NBS1 at DSBs, thereby enhancing repair by NHEJ [52]. NBS1 interacts with H3K36me2 in vitro and could potentially respond directly to increased H3K36me2 at DSBs [65]. The demethylase FBXL11 (KDM2A/JHDM1A) counteracts H3K36me2 and is inactivated upon DNA damage to allow H3K36me2 and efficient repair [52, 65]. Our work indicates that a SETMARcontrolled mechanism is also at play at deprotected telomeres, but unclear is if $\mathrm{H} 3 \mathrm{~K} 36 \mathrm{me} 2$ is induced at deprotected telomeres by SETMAR or other H3K36me2-HMTs. Our ChIP experiments indicated that H3K36me2 pre-exists at telomeres and did not detect increased H3K36me2 at (sub)telomeres upon telomere deprotection. However, we cannot exclude a local increase in H3K36me2 at the distal ends of deprotected telomeres that remains below detection in our ChIP experiments covering long telomeric distances. A limited local increase could underlie the increased H3K36me2 occasionally visible in immunoblots of TRF2ts cells undergoing telomere uncapping (e.g., Figure 4a). Whether H3K36me2-facilitated telomere-NHEJ involves effects on telomeric localization of $\mathrm{Ku}$ is difficult to discern since, besides binding DNA ends, Ku also localizes to telomeres via association with TRF1 and TRF2 [66-69]. Furthermore, it seems unlikely that NBS1 at telomeres is considerably affected by MMSET as MRN-dependent ATM activity was unperturbed in MMSET-depleted cells. While our data indicate that MMSET-dependent H3K36me2 is most likely important for further downstream steps of NHEJ at telomeres, such as those immediately preceding or at the actual DNA ligation step by XRCC4/Lig4, DNA-PKcs localization and autophosphorylation appeared normal in MMSET-depleted cells. Nevertheless, other components of the NHEJ-machinery could potentially be affected by MMSET and H3K36me2, e.g., XLF, PAXX, or XRCC4/Lig4. As MMSET was previously shown to facilitate XRCC4 recruitment to DNA damage [30], XRCC4 is a plausible candidate for being controlled by MMSET activity at deprotected telomeres. Unfortunately, technical limitations prohibited us from concluding whether MMSET promotes XRCC4 recruitment also to deprotected telomeres. As similar limitations apply to other NHEJ-components, the precise NHEJ-components at telomeres affected by MMSET remain elusive for now. 
Third, MMSET and its role in H3K36 methylation could impact on DNA repair by affecting global chromatin state. Both loss of yeast Set 2 and depletion of mammalian MMSET were reported to alter chromatin accessibility $[36,63,64]$. Furthermore, the histone deacetylases HDAC1 and HDAC2, which interact with MMSET, have also been implicated in NHEJ, including at uncapped telomeres $[16,70]$. Whether MMSET via interactions with HDACs affects acetylation at telomeres or whether an interplay between methylation and acetylation influences chromatin states at telomeres and thereby DNA repair, would be interesting to further investigate.

Finally, while our data indicate that MMSET impacts on telomere-NHEJ primarily through H3K36-methylation, it is possible that also nonhistone targets of MMSET contribute to c-NHEJ. Interestingly, MMSET was recently shown to dimethylate PTEN upon DNA damage, thereby aid PTEN recruitment to DNA damage via interaction with 53BP1, support PTEN phosphatase activity toward $\mathrm{H} 2 \mathrm{AX}$ and affect sensitivity to DNAdamaging agents [71]. Although $\mathrm{H} 2 \mathrm{AX}$ phosphorylation was not clearly affected in MMSET-depleted cells undergoing telomere uncapping, to what extent MMSETmediated methylation of PTEN or other potential nonhistone targets contribute to telomere-NHEJ is interesting to explore in future research.

Interestingly, our results indicate that while critical for cNHEJ, MMSET is dispensable for alt-NHEJ. The contribution of chromatin marks to c-NHEJ versus alt-NHEJ is still unclear. As alt-NHEJ shares the initial DNA resection steps with HR, it is conceivable that a chromatin environment facilitating resection and HR could also aid in altNHEJ [72]. However, while SETD2-dependent H3K36me3 promotes $\mathrm{HR}$ at active genes, SETD2 loss increased altNHEJ rather than impaired it, with alt-NHEJ serving as backup for ineffective HR [60, 62]. In our work, MMSET loss caused decreased H3K36me3, but did not increase altNHEJ at deprotected telomeres. Although high alt-NHEJ rates in our experimental system might technically prohibit detecting a further increase, we hypothesize that the effect of SETD2-mediated H3K36me3 on alt-NHEJ might be restricted to defined chromatin locations, such as active genes, and not apply to telomeres.

Aside from multiple myeloma, MMSET is overexpressed in a variety of cancers [73]. By promoting NHEJ, MMSET overexpression could potentially contribute to tumorigenesis through telomere-induced genomic instability or inappropriately favoring NHEJ for DNA repair, thereby elevating the risk of genomic translocations or other alterations. Indeed, MMSET overexpression increased NHEJ-efficiency at deprotected telomeres (Fig. 5e). Moreover, MMSET overexpression could potentially increase overall DNA repair-efficiency, which in established tumors might affect the efficacy of DNAdamaging therapies. Indeed, MMSET overexpressing cells show resistance to chemotherapy [30] and decreased sensitivity to IR (Fig. 5d). Therefore, inhibition of MMSET by small-molecule inhibitors in combination with DNAdamaging chemotherapeutics or IR could potentially be potent in treatment of cancers with increased MMSET expression. Better understanding of the mechanism by which MMSET functions in DNA repair will help further improve treatment opportunities for cancers with altered MMSET expression.

\section{Material and methods}

\section{Cells, growth and survival assays}

$\operatorname{Trf} 2^{-/-} ; p 53^{-/-}$;TRF2ts MEFs [18] were maintained at $32{ }^{\circ} \mathrm{C}$, Phoenix-eco cells, $293 \mathrm{~T}$ (ATCC), and other MEFs at $37^{\circ} \mathrm{C}$.

For short-term growth assays, TRF2ts MEFs were plated in triplicate at 5000 cells/well on 12-well plates and allowed to adhere overnight at $32^{\circ} \mathrm{C}$. Cells were incubated at $39^{\circ} \mathrm{C}$ to induce telomere uncapping for 12 days, fixed every 3 days using $4 \%$ formaldehyde and stained with $0.1 \%$ crystal violet. For quantification crystal violet was extracted with $10 \%$ acetic acid and absorbance at $595 \mathrm{~nm}$ was measured in a Tecan microplate reader.

For survival assays TRF2ts MEFs were plated at 45,000 cells $/ 10 \mathrm{~cm}$ plate or 150,000 cells $/ 15 \mathrm{~cm}$ plate, incubated at $39^{\circ} \mathrm{C}$ for 12 days and returned at $32{ }^{\circ} \mathrm{C}$ for $2-4$ weeks until crystal violet staining. One set of plates was stained after 7 days at $32{ }^{\circ} \mathrm{C}$ to control for potential toxicity of shRNAs. Culture details, viral transduction, cell cycle, and aneuploidy analysis by flow cytometry are detailed in Supplementary Materials and Methods.

\section{Methyltransferase screen}

$\operatorname{Trf} 2^{-/} ; p 53^{-/-} ;$TRF2ts MEFs were infected with a custommade pRetrosuper-shRNA library targeting 38 known or predicted methyltransferases with 4 shRNAs per gene, or with empty pRetrosuper. Library DNA was divided into 7 pools, viruses were produced per pool and infected separately. ShRNA sequences for the methyltransferase library and H3K36me2-HMTs are in Supplementary Materials and Methods. After selection for puromycin-resistance cells were plated $(150,000 / 15 \mathrm{~cm}$ dish) for survival assays.

\section{Telomere-fusion and G-overhang analysis}

Telomere-fusion assays using telomere-FISH were performed essentially as before [18, 32] and are further detailed in Supplementary Materials and Methods. 
$3^{\prime}$ single-stranded G-overhangs were analyzed using pulsed-field gel electrophoresis and in-gel hybridization with ${ }^{32} \mathrm{P}$-labeled (CCCTAA $)_{4}$-oligonucleotide as before $[18,32]$.

\section{qRT-PCR}

Total RNA extraction using TRIzol (Ambion), reverse transcription and qRT-PCR were performed using standard procedures and described in Supplementary Materials and Methods.

\section{Immunoblotting and histone extraction}

Preparation of whole-cell lysates and immunoblotting were done as before [32]. Primary and secondary antibodies and immunodetection methods are listed in Supplementary Materials and Methods.

For acid extraction of core histones, cells pellets were harvested and sequentially extracted with perchloric acid and $\mathrm{HCl}$, followed by precipitation of core histones with trichloroacetic acid. Histone pellets were sequentially washed with $100 \%$ Aceton $/ 0.006 \% \mathrm{HCl}$ and $100 \%$ Aceton, dried, and resuspended for protein concentration measurement (Bradford assay) and loading onto precast SDS-PAGE gels for immunoblotting. Additional details are in Supplementary Materials and Methods.

\section{IF, IF-FISH}

TRF2ts MEFs were seeded onto eight-well chamber slides (Millipore). For IF detection of $\gamma \mathrm{H} 2 \mathrm{AX}$, p-ATM, and 53BP1, cells were washed with PBS and fixed for $10 \mathrm{~min}$ with $2 \%$ paraformaldehyde (PFA). For p-DNA-PKcs, FK2 and BRCA1, cells were washed with PBS and pre-extracted with ice-cold $0.5 \%$ Triton/PBS on ice for $5 \mathrm{~min}$ prior to fixation in $2 \%$ PFA. Subsequent processing was done as before [32], further specified in Supplementary Materials and Methods.

For IF-FISH cells were pre-extracted with $0,5 \%$ triton/ PBS, fixed for $10 \mathrm{~min}$ with $2 \%$ PFA and $10 \mathrm{~min}$ on ice with methanol. Staining with primary antibody for 53BP1 (NB100-305, Novus, 1:500) and secondary antibody (Alexa Fluor 568, Invitrogen), FISH detection of telomere repeats with a FITC-OO-(CCCTAA) 3 PNA custom probe (Biosynthesis) and image acquisition were done as described [18].

\section{Chromatin immunoprecipitation}

$\operatorname{Trf} 2^{-/-} ; p 53^{-/}$;TRF2ts MEFs were crosslinked for $15 \mathrm{~min}$ with $1 \%$ formaldehyde. After $5 \mathrm{~min}$ in $0.2 \mathrm{M}$ Glycine and three washes with ice-cold PBS, cells were resuspended in $2 \mathrm{ml}$ lysis buffer with iodoacetamide, sodium butyrate, protease and phosphatase inhibitors. For chromatin preparation, $1 \mathrm{ml}$ triton dilution buffer (with inhibitors above) was added and lysates were sonicated on ice. ChIP was performed overnight at $4{ }^{\circ} \mathrm{C}$ with $\mathrm{IgG}$ rabbit isotype control or $\mathrm{H} 3 \mathrm{~K} 36 \mathrm{me} 2, \mathrm{H} 3$, or GFP antibodies pre-coupled to protein $A$ and protein $G$ magnetic beads. After multiple washes immunoprecipitated protein-DNA complexes were eluted, crosslinks were reversed and DNA was recovered and analyzed for (sub)telomeric DNA content by qRT-PCR or dot blots.

Further details are in Supplementary Materials and Methods.

\section{Statistics}

Statistical analyses were performed with GraphPad Prism using an unpaired two-tailed Student's $t$ test. Significances: not significant (ns) $p>0.05 ; * p \leq 0.05$; **p $\leq 0.01$; *** $p \leq$ $0.001 ; * * * * p \leq 0.0001$.

Acknowledgements We thank $\mathrm{T}$. de Lange for $\mathrm{TRF} 2^{\mathrm{I468 \textrm {A }}}, \operatorname{Tr} \mathrm{2}^{\text {flox/-}}$; $p 53^{-1-}$ and $\operatorname{Trf1} 1^{F / F} ; \operatorname{Trf} 2^{F / F} ; K u 70^{-/-}$MEFs, K. Braat, B. Westerman and M. van Lohuizen for methyltransferase shRNAs, K. Ura for MMSET plasmids and $\mathrm{Mmset}^{-/-}$MEFs, J. Jonkers for mBRCA1

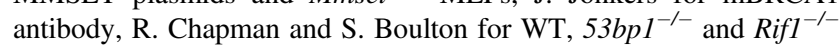
MEFs, R. Thakar and C. Azzalin for pLPC-GFP-TRF1, J-H. Dannenberg for pDONR223-FBXL11, B. van den Broek for ImageJ Macros and M. Mertz for supporting image processing. This work was supported by Grant ALW822.02.004 from the Dutch Research Council to JJLJ and a Boehringer Ingelheim Fonds PhD scholarship to $\mathrm{IdK}$.

\section{Compliance with ethical standards}

Conflict of interest The authors declare that they have no conflict of interest.

Publisher's note Springer Nature remains neutral with regard to jurisdictional claims in published maps and institutional affiliations.

Open Access This article is licensed under a Creative Commons Attribution 4.0 International License, which permits use, sharing, adaptation, distribution and reproduction in any medium or format, as long as you give appropriate credit to the original author(s) and the source, provide a link to the Creative Commons license, and indicate if changes were made. The images or other third party material in this article are included in the article's Creative Commons license, unless indicated otherwise in a credit line to the material. If material is not included in the article's Creative Commons license and your intended use is not permitted by statutory regulation or exceeds the permitted use, you will need to obtain permission directly from the copyright holder. To view a copy of this license, visit http://creativecommons. org/licenses/by/4.0/.

\section{References}

1. Lukas J, Lukas C, Bartek J. More than just a focus: the chromatin response to DNA damage and its role in genome integrity maintenance. Nat Cell Biol. 2011;13:1161-9. 
2. Botuyan MV, Lee J, Ward IM, Kim JE, Thompson JR, Chen J, et al. Structural basis for the methylation state-specific recognition of histone $\mathrm{H} 4-\mathrm{K} 20$ by 53BP1 and Crb2 in DNA repair. Cell. 2006;127:1361-73.

3. Fradet-Turcotte A, Canny MD, Escribano-Diaz C, Orthwein A, Leung $\mathrm{CC}$, Huang $\mathrm{H}$, et al. 53BP1 is a reader of the DNAdamage-induced H2A Lys 15 ubiquitin mark. Nature. 2013;499:50-4.

4. Tang J, Cho NW, Cui G, Manion EM, Shanbhag NM, Botuyan $\mathrm{MV}$, et al. Acetylation limits 53BP1 association with damaged chromatin to promote homologous recombination. Nat Struct Mol Biol. 2013;20:317-25.

5. Hsiao KY, Mizzen CA. Histone $\mathrm{H} 4$ deacetylation facilitates 53BP1 DNA damage signaling and double-strand break repair. J Mol Cell Biol. 2013;5:157-65.

6. Jacquet K, Fradet-Turcotte A, Avvakumov N, Lambert JP, Roques C, Pandita RK, et al. The TIP60 complex regulates bivalent chromatin recognition by 53BP1 through direct H4K20me binding and H2AK15 acetylation. Mol Cell. 2016;62:409-21.

7. Fortuny A, Polo SE. The response to DNA damage in heterochromatin domains. Chromosoma. 2018;127:291-300.

8. Clouaire T, Legube G. DNA double strand break repair pathway choice: a chromatin based decision? Nucleus 2015;6:107-13.

9. de Lange T. How shelterin solves the telomere end-protection problem. Cold Spring Harb Symp Quant Biol. 2010;75:167-77.

10. Arnoult N, Karlseder J. Complex interactions between the DNAdamage response and mammalian telomeres. Nat Struct Mol Biol. 2015;22:859-66.

11. Blasco MA. The epigenetic regulation of mammalian telomeres. Nat Rev Genet. 2007;8:299-309.

12. O'Sullivan RJ, Karlseder J. Telomeres: protecting chromosomes against genome instability. Nat Rev Mol cell Biol. 2010;11:171-81.

13. Benetti R, Garcia-Cao M, Blasco MA. Telomere length regulates the epigenetic status of mammalian telomeres and subtelomeres. Nat Genet. 2007;39:243-50.

14. Takai H, Smogorzewska A, de Lange T. DNA damage foci at dysfunctional telomeres. Curr Biol. 2003;13:1549-56.

15. Celli GB, de Lange T. DNA processing is not required for ATMmediated telomere damage response after TRF2 deletion. Nat Cell Biol. 2005;7:712-8.

16. Bartocci C, Diedrich JK, Ouzounov I, Li J, Piunti A, Pasini D, et al. Isolation of chromatin from dysfunctional telomeres reveals an important role for Ring $1 \mathrm{~b}$ in NHEJ-mediated chromosome fusions. Cell Rep. 2014;7:1320-32.

17. Porro A, Feuerhahn S, Delafontaine J, Riethman H, Rougemont J, Lingner J. Functional characterization of the TERRA transcriptome at damaged telomeres. Nat Commun. 2014;5:5379.

18. Peuscher $\mathrm{MH}$, Jacobs JJ. DNA-damage response and repair activities at uncapped telomeres depend on RNF8. Nat cell Biol. 2011;13:1139-45.

19. Luijsterburg MS, de Krijger I, Wiegant WW, Shah RG, Smeenk $\mathrm{G}$, de Groot AJL, et al. PARP1 links CHD2-mediated chromatin expansion and H3.3 deposition to DNA repair by nonhomologous end-joining. Mol Cell. 2016;61:547-62.

20. Chesi M, Nardini E, Lim RS, Smith KD, Kuehl WM, Bergsagel PL. The $\mathrm{t}(4 ; 14)$ translocation in myeloma dysregulates both FGFR3 and a novel gene, MMSET, resulting in IgH/MMSET hybrid transcripts. Blood. 1998;92:3025-34.

21. Stec I, Wright TJ, van Ommen GJ, de Boer PA, van Haeringen A, Moorman AF, et al. WHSC1, a 90 kb SET domain-containing gene, expressed in early development and homologous to a Drosophila dysmorphy gene maps in the Wolf-Hirschhorn syndrome critical region and is fused to $\operatorname{IgH}$ in $\mathrm{t}(4 ; 14)$ multiple myeloma. Hum Mol Genet. 1998;7:1071-82.
22. Nimura K, Ura K, Shiratori H, Ikawa M, Okabe M, Schwartz RJ, et al. A histone $\mathrm{H} 3$ lysine 36 trimethyltransferase links Nkx2-5 to Wolf-Hirschhorn syndrome. Nature. 2009;460:287-91.

23. Bergemann AD, Cole F, Hirschhorn K. The etiology of WolfHirschhorn syndrome. Trends Genet 2005;21:188-95.

24. Kuo AJ, Cheung P, Chen K, Zee BM, Kioi M, Lauring J, et al. NSD2 links dimethylation of histone $\mathrm{H} 3$ at lysine 36 to oncogenic programming. Mol Cell. 2011;44:609-20.

25. Lauring J, Abukhdeir AM, Konishi H, Garay JP, Gustin JP, Wang $\mathrm{Q}$, et al. The multiple myeloma associated MMSET gene contributes to cellular adhesion, clonogenic growth, and tumorigenicity. Blood. 2008;111:856-64.

26. Hudlebusch HR, Santoni-Rugiu E, Simon R, Ralfkiaer E, Rossing $\mathrm{HH}$, Johansen JV, et al. The histone methyltransferase and putative oncoprotein MMSET is overexpressed in a large variety of human tumors. Clin Cancer Res. 2011;17:2919-33.

27. Kassambara A, Klein B, Moreaux J. MMSET is overexpressed in cancers: link with tumor aggressiveness. Biochem Biophys Res Commun. 2009;379:840-5.

28. Pei H, Zhang L, Luo K, Qin Y, Chesi M, Fei F, et al. MMSET regulates histone $\mathrm{H} 4 \mathrm{~K} 20$ methylation and 53BP1 accumulation at DNA damage sites. Nature. 2011;470:124-8.

29. Hajdu I, Ciccia A, Lewis SM, Elledge SJ. Wolf-Hirschhorn syndrome candidate 1 is involved in the cellular response to DNA damage. Proc Natl Acad Sci USA. 2011;108:13130-4.

30. Shah MY, Martinez-Garcia E, Phillip JM, Chambliss AB, Popovic R, Ezponda T, et al. MMSET/WHSC1 enhances DNA damage repair leading to an increase in resistance to chemotherapeutic agents. Oncogene. 2016;35:5905-15.

31. Konishi A, de Lange T.Cell cycle control of telomere protection and NHEJ revealed by a Ts mutation in the DNA-binding domain of TRF2.Genes \& Dev.2008;22:1221-30.

32. Boersma V, Moatti N, Segura-Bayona S, Peuscher MH, van der Torre J, Wevers BA, et al. MAD2L2 controls DNA repair at telomeres and DNA breaks by inhibiting 5 ' end resection. Nature. 2015;521:537-40.

33. Sfeir A, de Lange T. Removal of shelterin reveals the telomere end-protection problem. Science. 2012;336:593-7.

34. Smogorzewska A, Karlseder J, Holtgreve-Grez H, Jauch A, de Lange T. DNA ligase IV-dependent NHEJ of deprotected mammalian telomeres in G1 and G2. Curr Biol. 2002;12:1635-44.

35. Li Y, Trojer P, Xu CF, Cheung P, Kuo A, Drury WJ 3rd, et al. The target of the NSD family of histone lysine methyltransferases depends on the nature of the substrate. J Biol Chem. 2009;284:34283-95.

36. Martinez-Garcia E, Popovic R, Min DJ, Sweet SM, Thomas PM, Zamdborg L, et al. The MMSET histone methyl transferase switches global histone methylation and alters gene expression in $\mathrm{t}$ (4;14) multiple myeloma cells. Blood. 2011;117:211-20.

37. Coussens NP, Kales SC, Henderson MJ, Lee OW, Horiuchi KY, Wang Y, et al. High-throughput screening with nucleosome substrate identifies small-molecule inhibitors of the human histone lysine methyltransferase NSD2. J Biol Chem. 2018;293:13750-65.

38. Wagner EJ, Carpenter PB. Understanding the language of Lys36 methylation at histone H3. Nat Rev Mol Cell Biol. 2012;13:115-26.

39. Edmunds JW, Mahadevan LC, Clayton AL. Dynamic histone H3 methylation during gene induction: $\mathrm{HYPB} / \mathrm{Setd} 2$ mediates all H3K36 trimethylation. EMBO J. 2008;27:406-20.

40. Clouaire T, Rocher V, Lashgari A, Arnould C, Aguirrebengoa M, Biernacka A, et al. Comprehensive mapping of histone modifications at DNA double-strand breaks deciphers repair pathway chromatin signatures. Mol Cell. 2018;72:250-62 e6.

41. Dimitrova N, de Lange T. Cell cycle-dependent role of MRN at dysfunctional telomeres: ATM signaling-dependent induction of 
nonhomologous end joining (NHEJ) in G1 and resection-mediated inhibition of NHEJ in G2. Mol Cell Biol. 2009;29:5552-63.

42. Bunting SF, Callen E, Wong N, Chen HT, Polato F, Gunn A, et al. 53BP1 inhibits homologous recombination in Brcal-deficient cells by blocking resection of DNA breaks. Cell. 2010;141: 243-54.

43. Zimmermann M, Lottersberger F, Buonomo SB, Sfeir A, de Lange T. 53BP1 regulates DSB repair using Rif1 to control 5' end resection. Science. 2013;339:700-4.

44. Chapman JR, Barral P, Vannier JB, Borel V, Steger M, TomasLoba A, et al. RIF1 is essential for 53BP1-dependent nonhomologous end joining and suppression of DNA double-strand break resection. Mol Cell. 2013;49:858-71.

45. Di Virgilio M, Callen E, Yamane A, Zhang W, Jankovic M, Gitlin $\mathrm{AD}$, et al. Rif1 prevents resection of DNA breaks and promotes immunoglobulin class switching. Science. 2013;339:711-5.

46. Escribano-Diaz C, Orthwein A, Fradet-Turcotte A, Xing M, Young JT, Tkac J, et al. A cell cycle-dependent regulatory circuit composed of 53BP1-RIF1 and BRCA1-CtIP controls DNA repair pathway choice. Mol Cell. 2013;49:872-83.

47. Symington LS. Mechanism and regulation of DNA end resection in eukaryotes. Crit Rev Biochem Mol. Biol. 2016;51:195-212.

48. Hartlerode AJ, Guan Y, Rajendran A, Ura K, Schotta G, Xie A, et al. Impact of histone $\mathrm{H} 4$ lysine 20 methylation on 53BP1 responses to chromosomal double strand breaks. PLoS ONE. 2012;7:e49211.

49. Tuzon CT, Spektor T, Kong X, Congdon LM, Wu S, Schotta G, et al. Concerted activities of distinct H4K20 methyltransferases at DNA double-strand breaks regulate 53BP1 nucleation and NHEJdirected repair. Cell Rep. 2014;8:430-8.

50. Blackford AN, Jackson SP. ATM, ATR, and DNA-PK: The Trinity at the Heart of the DNA Damage Response. Mol Cell 2017;66:801-17.

51. Jiang W, Crowe JL, Liu X, Nakajima S, Wang Y, Li C, et al. Differential phosphorylation of DNA-PKcs regulates the interplay between end-processing and end-ligation during nonhomologous end-joining. Mol Cell. 2015;58:172-85.

52. Fnu S, Williamson EA, De Haro LP, Brenneman M, Wray J, Shaheen M, et al. Methylation of histone H3 lysine 36 enhances DNA repair by nonhomologous end-joining. Proc Natl Acad Sci USA. 2011;108:540-5.

53. Tsukada Y, Fang J, Erdjument-Bromage H, Warren ME, Borchers $\mathrm{CH}$, Tempst $\mathrm{P}$, et al. Histone demethylation by a family of JmjC domain-containing proteins. Nature. 2006;439:811-6.

54. Pei H, Wu X, Liu T, Yu K, Jelinek DF, Lou Z. The histone methyltransferase MMSET regulates class switch recombination. J Immunol. 2013;190:756-63.

55. Nguyen HV, Dong J, Panchakshari RA, Kumar V, Alt FW, Bories JC. Histone methyltransferase MMSET promotes AID-mediated DNA breaks at the donor switch region during class switch recombination. Proc Natl Acad Sci USA. 2017;114:E10560-7.

56. Marango J, Shimoyama M, Nishio H, Meyer JA, Min DJ, Sirulnik A, et al. The MMSET protein is a histone methyltransferase with characteristics of a transcriptional corepressor. Blood. 2008;111:3145-54.

57. Todoerti K, Ronchetti D, Agnelli L, Castellani S, Marelli S, Deliliers GL, et al. Transcription repression activity is associated with the type I isoform of the MMSET gene involved in $\mathrm{t}(4 ; 14)$ in multiple myeloma. Br J Haematol. 2005;131:214-8.

58. Kim JY, Kee HJ, Choe NW, Kim SM, Eom GH, Baek HJ, et al. Multiple-myeloma-related WHSC1/MMSET isoform RE-IIBP is a histone methyltransferase with transcriptional repression activity. Mol Cell Biol. 2008;28:2023-34.

59. Popovic R, Martinez-Garcia E, Giannopoulou EG, Zhang Q, Zhang Q, Ezponda T, et al. Histone methyltransferase MMSET/ NSD2 alters EZH2 binding and reprograms the myeloma epigenome through global and focal changes in H3K36 and H3K27 methylation. PLoS Genet. 2014;10:e1004566.

60. Pfister SX, Ahrabi S, Zalmas LP, Sarkar S, Aymard F, Bachrati $\mathrm{CZ}$, et al. SETD2-dependent histone H3K36 trimethylation is required for homologous recombination repair and genome stability. Cell Rep. 2014;7:2006-18.

61. Carvalho S, Vitor AC, Sridhara SC, Martins FB, Raposo AC, Desterro JM, et al. SETD2 is required for DNA double-strand break repair and activation of the p53-mediated checkpoint. Elife. 2014;3:e2482.

62. Aymard F, Bugler B, Schmidt CK, Guillou E, Caron P, Briois S, et al. Transcriptionally active chromatin recruits homologous recombination at DNA double-strand breaks. Nat Struct Mol Biol. 2014;21:366-74.

63. Pai CC, Deegan RS, Subramanian L, Gal C, Sarkar S, Blaikley EJ, et al. A histone H3K36 chromatin switch coordinates DNA doublestrand break repair pathway choice. Nat Commun. 2014;5:4091.

64. Jha DK, Strahl BD. An RNA polymerase II-coupled function for histone H3K36 methylation in checkpoint activation and DSB repair. Nat Commun. 2014;5:3965.

65. Cao LL, Wei F, Du Y, Song B, Wang D, Shen C, et al. ATMmediated KDM2A phosphorylation is required for the DNA damage repair. Oncogene. 2016;35:301-13.

66. Hsu HL, Gilley D, Galande SA, Hande MP, Allen B, Kim SH, et al. $\mathrm{Ku}$ acts in a unique way at the mammalian telomere to prevent end joining. Genes Dev. 2000;14:2807-12.

67. Ribes-Zamora A, Indiviglio SM, Mihalek I, Williams CL, Bertuch AA. TRF2 interaction with $\mathrm{Ku}$ heterotetramerization interface gives insight into c-NHEJ prevention at human telomeres. Cell Rep. 2013;5:194-206.

68. Celli GB, Denchi EL, de Lange T. Ku70 stimulates fusion of dysfunctional telomeres yet protects chromosome ends from homologous recombination. Nat Cell Biol. 2006;8:885-90.

69. de Lange T. How telomeres solve the end-protection problem. Science. 2009;326:948-52.

70. Miller KM, Tjeertes JV, Coates J, Legube G, Polo SE, Britton S, et al. Human HDAC1 and HDAC2 function in the DNA-damage response to promote DNA nonhomologous end-joining. Nat Struct Mol Biol. 2010;17:1144-51.

71. Zhang J, Lee YR, Dang F, Gan W, Menon AV, Katon JM, et al. PTEN methylation by NSD2 controls cellular sensitivity to DNA damage. Cancer Discov. 2019;9:1306-23.

72. Sallmyr A, Tomkinson AE. Repair of DNA double-strand breaks by mammalian alternative end-joining pathways. J Biol Chem. 2018;293:10536-46.

73. Bennett RL, Swaroop A, Troche C, Licht JD. The role of nuclear receptor-binding set domain family histone lysine methyltransferases in cancer. Cold Spring Harb Perspect Med. 2017;7:6. 